\title{
Effect of an Education Program on Nurses Performance Regarding Electrocardiography
}

\author{
Rasha Nabil Malk*, Kamelia Fouad Abd-Allah**, Mostafa Mostafa Rezk* and Sabah Said \\ Mohammed* \\ * Medical Surgical Nursing Department Faculty of Nursing, Benha University. \\ ** Medical Surgical Nursing Department Faculty of Nursing, Ain Shams University
}

\begin{abstract}
The ECG is a non-invasive, effective, simple cardiac test and useful in diagnosing cardiac disorders and detecting any arrhythmia. It plays a critical role in reducing morbidity and mortality in patients with coronary artery disease. Nurses working in critical care areas are responsible for monitoring and interpreting ECGs. Aim of this study is to evaluate the effect of an education program on nurses' performance (knowledge and practice) regarding electrocardiography. Design: A quasi-experimental design was used. Setting: this study was conducted in the coronary units at Benha University Hospital. Sample: all nurses $(n=32)$ working at coronary units. Tools: Two tools were used a self administered questionnaire sheet to assess knowledge and observational checklist to assess practice regarding electrocardiography. Results: this study showed that the majority of the nurses had unsatisfactory knowledge and practice regarding electrocardiography pre program implementation $(96.9 \%$ and $87.1 \%$ respectively) which improved significally immediately post program (90.6\% and $87.5 \%$ respectively) p value $<0.001$, while this improvement lowered slightly post 3 months at follow up $(78.1 \%$ and $81.2 \%$ respectively). Conclusion: the majority of the nurses were having an unsatisfactory performance (knowledge and practice) regarding electrocardiography pre the program implementation. Meanwhile, the majority of the studied nurses had got statistically significant improvement in their performance post the program implementation, while this improvement lowered slightly post three months at follow up, which supported the study hypothesis. Recommendation that the importane of continuous in-service training programs about ECG for the purpose of refreshing, updating the nurses knowledge and practice regarding ECG.
\end{abstract}

Key words: electrocardiography, nurses, performance.

Introduction

Electrocardiogram is a graphical recording of electrical activity of the heart (Jacob et al., 2015). It is considered effective, simple, noninvasive, low-cost procedures for the diagnosis of cardiovascular diseases (CVDs) and detecting any arrhythmia (Zhu et al., 2013).
The 12- lead ECG is used to diagnose dysrhythmias, conduction abnormalities, and chamber enlargement, as well as myocardial ischemia, injury, or infarction. It can also suggest cardiac effects of electrolyte disturbances (high or low calcium and potassium levels) and the effects of anti 
arrhythmic medications (Hinkle and Cheever, 2014).

As regards nursing role regarding ECG, the nurse should explain the procedure to the patient. Ensure privacy, and expose the patient's wrists, ankles, and chest and draping him appropriately. Remove jewelry and metal. Ask the patient to lie still and avoiding movement. Place leads and make sure ECG is plugged in and interpret rhythm strip (Nettina, 2014).

The interpretation of cardiac rhythm disturbances or dysrhythmias is an essential skill for nurses employed in patient care areas where electrocardiographic monitoring occurs. The ability to rapidly analyze a rhythm disturbance as well as initiate appropriate treatment improves patient safety and optimizes successful outcomes. The critical care nurse is often the healthcare professional responsible for the continuous monitoring of the patient's cardiac rhythm and has the opportunity to provide early intervention that can prevent an adverse clinical situation(Marcum, 2013).

Every nurse has the professional responsibility to attain knowledge and skills to improve practice. Likewise, every critical care nurse has a responsibility to use best evidence in the delivery of patient care (Fitzpatrick, 2013). The purpose of continuing education in nursing is to enhance knowledge, skills, and confidence of professional nurses to provide high-quality, competent, and safe patient care(Tame, 2013).

\section{Significance of the study:-}

The 12-lead ECG plays a critical role in reducing morbidity and mortality in patients with coronary artery disease because it enables the practitioner to detect early danger signs. (Rahr and Ayachi, 2013). The ability to recognize arrhythmias is an essential skill for the nurse. Prompt assessment of an abnormal cardiac rhythm and patient response to the rhythm is critical (Basavanthappa, 2015).

Nurses working in critical care areas are responsible for monitoring and interpreting ECGs, patients usually are monitored continuously at the bedside and have intermittent monitoring through a 12lead ECG (Linton, 2016).

\section{Aim of the study:}

The aim of the current study is to evaluate the effect of an education program on nurses' performance regarding electrocardiography.

\section{Research Hypothesis:}

There will be a positive change in the level of nurses' performance post implementation of an education program through improving their knowledge and practice regarding electrocardiography.

\section{Subjects and Methods}

The study will be portrayed under four designs:-

- Technical design.

- Operational design.

- Administrative design.

- Statistical design.

\section{Technical design:}

The technical design includes research design, setting, subjects and tools of data collection which used in this study.

\section{Research Design:}

A quasi-experimental design was used in this study. 


\section{A. Setting:}

The study was conducted in the coronary care unit at Benha University Hospitals.

\section{B. Subject:}

A convenient sample included 32 nurses working in coronary care unit at Benha University Hospitals and agreed to participate in this study.

\section{Tools of data collection:}

Two tools will be used to collect data of this study, these tools are: -

\section{A self administered questionnaire:}

It was used to assess nurses' level of knowledge regarding electrocardiography. It was developed by the researcher based on review of related literature (Ali, et al., 2012,Malk, et al., 2013, Eckman, 2013, Williams, 2015 and Clutter, 2015). It compromised Arabic structured items related to different aspects of assessment knowledge about electrocardiography. It was including two parts:

\section{* Part one:}

It concerned with demographic characteristics of the nurses involved in the study (age, gender, marital status, level of education, years of experience and years of experience in coronary care unit)

\section{* Part two:}

It concerned with assessment of the knowledge related (anatomy and physiology of the heart (3 questions), electrocardiography(5 questions), role of the nurse regarding ECG (3 questions), characteristics of normal ECG (7 questions), characteristics of abnormal ECG (10 questions), nursing role for patient with cardiac arrhythmia (10 questions), interpretation of type of arrhythmia (16 questions).

This tool was filled three times; the first times before the program implementation, the second time immediately after program implementation and the third time after 3 months later (follow up).

\section{Scoring system:}

All knowledge variables were closed ended questions. The total numbers were 54 questions; they were scored as the following.

- Each correct answer was given one grade

- The incorrect answer was given zero.

Total knowledge score was classified as the following:

- $\quad \geq 80 \%$ satisfactory knowledge level --score $\geq 43$.

- $\quad<80 \%$ unsatisfactory knowledge level--score $<43$.

II. Nurse practice observational checklist regarding their role towards electrocardiography:

It was adapted from Eckman, (2013) and modified by the researcher. It was used to assess nurses' practice regarding electrocardiography. This tool was filled three times; the first times before the program implementation, the second time immediately after program implementation and the third time after 3 month later (follow up).

\section{Scoring system:}

- Done correctly was assigned a score of (2) 
- Done incorrectly was assigned a score of (1)

- Not done was assigned a score of (0)

Total practice score was $29 \times 2=58$ into:

Total score of practice was classified

- $\quad \geq 80 \%$ satisfactory practice level--- score $\geq 46$.

- $\quad<80 \%$ unsatisfactory practice level--score $<46$.

The total score was distributed as the following:

- $\quad$ Nurses role pre procedure (8 steps) (16 grades).

- Nurses role during procedure (9 steps) (18 grades).

- $\quad$ Nurses role post procedure (4 steps) $(8$ grades).

- Interpreting the ECG (8 steps) (16 grades).

\section{Tools validity and reliability:}

\section{- Content validity:}

The tools were revised for content validity by a jury of seven experts who composed of 2 professors of medical surgical nursing from Ain Shams, one professors of medical surgical nursing from Alexandria University, one assistant professors of medical surgical nursing from Ain Shams and 3 lecturers of medical surgical nursing from Ain Shams University. The expertise reviewed the tool for objectivity, clarity, appropriately and comprehensiveness, minor modification was done.

\section{Operational design}

The operational design included a preparatory phase, pilot study, ethical consideration and field work.

\section{- Pilot study:}

It was carried out on $10 \%$ of the total study. This was done to test applicability, clarity and efficiency of the tools. No modification was done, so the nurses who shared in the pilot study were included in the sample.

\section{Ethical consideration:}

1. The researcher was clarifying the objective and aim of the study to the nurses included in the study.

2. The researcher was assured maintaining privacy of the subject's data for the purpose of this research only and will not be used again without new consent.

3. Nurses were informed about their rights to participate or withdraw from the study at any time without any rational. As well, the results of this study will not have any effect on their job.

\section{Field work:}

Data were collected from the beginning December 2015 to the end of September 2016. The program was implemented for nurses working in coronary care unit at Benha University Hospitals.

\section{Program phase:}

\section{Preparatory phase:}

It was included reviewing of related literature and theoretical knowledge of various aspect of the study using books, articles, internet, periodicals and magazines 
to develop tools for data collection and the training program for nurses.

The program implementation schedule was designed by the researcher. Goals, learning activity, teaching methods and media were prepared. The content of the educational program was divided into 5 sessions; the duration of each session is one hour.

Permission for data collection and implementation of the study in Benha University hospital was obtained from the hospital administrative personnel by the submission of a formal letter from the faculty of nursing, Benha University. Meeting and discussions were held by the researcher and nurses to explain the aims, the nature and the objectives of the study and take their approval to participate in the study prior to any data collection.

\section{Electrocardiography educational booklet:}

It was designed in Arabic language by researcher based on the results obtained from assessment of the nurses' knowledge and practice. which included anatomy and physiology of the heart, electrical conduction system of the heart, definition of ECG, purposes of ECG, complication of ECG, precautions of ECG, role of the nurse, heart rate calculation through ECG strip, characteristics of normal ECG, characteristics of abnormal ECG and role of the nurse. The content was developed by the researcher after reviewing the related literature (Diehl, 2012, Ali, et al., 2012,Malk, et al., 2013, Eckman, 2013, Ignatavicius and Workman, 2013, Hales, 2014, Bucher, et al., 2014, Williams, 2015, Clutter, 2015).

\section{Program assessment:}

The researcher was assessing of nurse's knowledge and practice about electrocardiography at Benha University Hospital by used questionnaire and observational checklist. The researcher was attended to the setting 3 days per week in the morning and afternoon shift.

1) As regards to the observational checklist the evaluation was done firstly to assess of nurse's practice regarding electrocardiography.

2) As regards to the questionnaire it was carried to assess of nurse's knowledge regarding electrocardiography that was filled by the nurse.

The observational checklist was filled by the researcher by observing the nurses while they were doing the ECG procedure; the time allowed is 15 minutes. The questionnaire was filled by the nurses, the time allowed for fulfilling it took about 2030 minutes.

Assessment of nurse's knowledge and practice was carried out three times firstly before education program, secondly immediately and thirdly after three months.

\section{- Program implementation:}

1. The program content was based on the studied nurses' needs assessment (knowledge and practice).

2. It was included four sessions for theoretical and practical part.

3. The content of educational program sessions was organized as the following.

\section{The theoretical part:}

- Introduction of training program and anatomy, physiology of the heart including objective of training program, anatomy of the heart, circulation of the heart and electrical conduction of the heart. 
- Electrocardiography (definition of the ECG, purpose of the ECG, complication of the ECG, precautions of ECG, ECG machine, leads of the ECG, component of the ECG).

- Role of the nursewith ECG (Role of the nurse pre, during, post ECG procedure).

- ECG Interpretation(characteristics of normal ECG, calculate heart rate through ECG strip, interpretation of normal ECG, artifacts and role of the nurse, arrhythmia originating in the sinus node and role the of nurse, arrhythmia originating in the atria and role of the nurse, arrhythmia originating in the ventricular and role of the nurse and arrhythmia originating in the AV node and role of the nurse.

\section{The practical part:}

Role of the nurse with ECG (role of the nurse pre, during, post ECG procedure).

\section{Teaching methods:}

- Lecture

- Discussion

- Teaching on spot

- Practical exercise.

\section{Teaching media:}

- Hand out of the program and schedule.

- Data show

- Booklet

- $\quad$ Picture

- $\quad$ Laptop
- $\quad$ ECG machine

- $\quad$ Video

- Photos

After the official permission were taken from director of Benha university hospital and nursing director, the implementation phase started.

The program was implemented over 12week period. The duration of each session is one hour, including periods of discussion according to nurses' progress and feedback. The researcher was available 3 days per week in the morning and afternoon shift in coronary care unit at Benha University Hospital.

At the beginning of the first session, an orientation to the program and its aims took place. Simple words and Arabic language were used to suit the nurses' level of understanding. Each session started by revision about what was given in previous session and the objective of new topics. The booklet was distributed to all nurses in the first day of program implementation.

\section{The Evaluation stage:}

After implementation of an education program, the post test was administered to assess nurses' knowledge and practice using the same questionnaire sheet and same observational checklist of the pre- test. It was done twice, immediately after finishing education program and after three months from first evaluation, this helped to evaluate the effect of the implementing program.

\section{Administrative design:}

To carry out the study, the necessary approval was obtained from the director of Benha university hospital. A letter was issued to him from the faculty of nursing explaining 
the aim of the study in order to obtain permission for collection of data.

\section{Statistical Design:}

An IBM compatible personal computer was used to store and analyze data and to produce graphic presentation for some important results. Statistical package for the social science (SPSS) version 22 was used for statistical analysis of data, as it contains the test of significance given in standard statistical books.

\section{- Descriptive statistics}

Data were summarized using 1) the arithmetic mean as an average, describing the central tendency of observation for each variable studied; 2) the standard deviation as a measure of dispersion of results around the mean; and 3) the frequency and percentage of observations for each variable studied. Other statistical tests such as chi-square test correlation coefficient was calculated between socio-demographic data and total knowledge score and between total knowledge score and total practice score and alpha Cronbach test was used to test reliability of the tool.

\section{- Level of Significance}

For all statistical tests done, the threshold of significance was fixed at the 5\% level (P-value). A p-value $>0.05$ indicates non-significant result and the p-value $<0.05$ indicates a significant result and the p-value is the degree of significance. The smaller the p-value obtained, the more significant is the result; the p-value being the probability of error of the conclusion.

\section{Results}

Table (1): Demonstrates that half of the studied nurses' $(50.0 \%)$ their age ranged between (25- 30) with a mean age was $(26.1250 \pm 3.34809)$ years, the majority $(93.8 \%)$ of nurses were females, most $(81.2 \%)$ of nurses were married. Regarding educational qualification $(40.6 \%)$ of the studied nurses' had technical nursing education. As regard the nurses' year of work $(56.3 \%)$ of the studied nurses' were from 5 - 10 years of work with a mean years of work was $(6.4375 \pm 3.79888)$ years. Regarding the nurses' years of experience in CCU $(50.0 \%)$ of them were having from (1$5)$ with a mean years of experience in $\mathrm{CCU}$ was $(5.6563 \pm 3.87389)$ years.

Fig. (1) illustrates that $96.9 \%$ of the studied nurses had unsatisfactory knowledge preprogram implementation which improved immediately post program and follow up program $(90.6 \%$ and $78.1 \%)$ of the studied nurses had satisfactory knowledge regarding electrocardiography respectively. Fig. (2) illustrates that $87.1 \%$ of the studied nurses had unsatisfactory practice preprogram implementation which improved immediately post program and follow up program $(87.5 \%$ and $81.2 \%$ ) of the studied nurses had satisfactory practice regarding electrocardiography respectively.

Table (2): demonstrates that a highly significant positive correlation between nurses' knowledge and practice at different phases of program implementation (pre, post and follow up program) with $\mathrm{r}$ and $\mathrm{p}$ value (.543/ $0.001, \quad .851 / .000, \quad .684 / .000)$ respectively. 


\section{Results:}

Table (1): Percentage distribution of the study nurses according to their demographic characteristics

\begin{tabular}{|c|c|c|}
\hline Variable & Frequency & $\%$ \\
\hline \multicolumn{3}{|l|}{ Age in years } \\
\hline $18-<25$ & 10 & 31.2 \\
\hline $25-<30$ & 16 & 50.0 \\
\hline $30-35$ & 6 & 18.8 \\
\hline Mean \pm SD & \multicolumn{2}{|l|}{$26.1250 \pm 3.34809$} \\
\hline \multicolumn{3}{|l|}{ Gender } \\
\hline Male & 2 & 6.2 \\
\hline Female & 30 & 93.8 \\
\hline \multicolumn{3}{|l|}{ Marital status } \\
\hline single & 6 & 18.8 \\
\hline Married & 26 & 81.2 \\
\hline \multicolumn{3}{|l|}{ Educational qualification } \\
\hline Secondary nursing education & 12 & 37.5 \\
\hline Technical nursing education & 13 & 40.6 \\
\hline Bachelor of nursing & 7 & 21.9 \\
\hline \multicolumn{3}{|l|}{ Years of work } \\
\hline $1-<5$ & 12 & 37.5 \\
\hline $5-<10$ & 18 & 56.3 \\
\hline$\geq 10$ & 2 & 6.2 \\
\hline Mean \pm SD & \multicolumn{2}{|l|}{$6.4375 \pm 3.79888$} \\
\hline \multicolumn{3}{|l|}{ Years of experience in CCU } \\
\hline $1-<5$ & 16 & 50.0 \\
\hline $5-<10$ & 15 & 46.9 \\
\hline$\geq 10$ & 1 & 3.1 \\
\hline Mean \pm SD & \multicolumn{2}{|l|}{$5.6563 \pm 3.87389$} \\
\hline
\end{tabular}

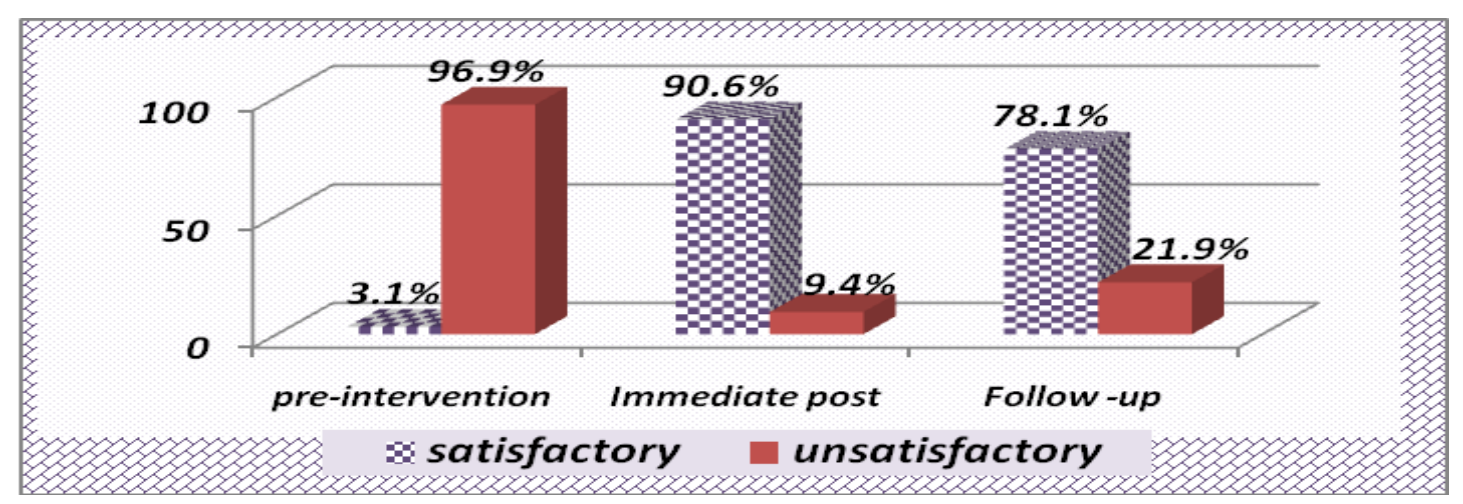

Fig. (1): Percentage distribution of studied nurses' total knowledge score regarding electrocardiography at different phases of program implementation. 


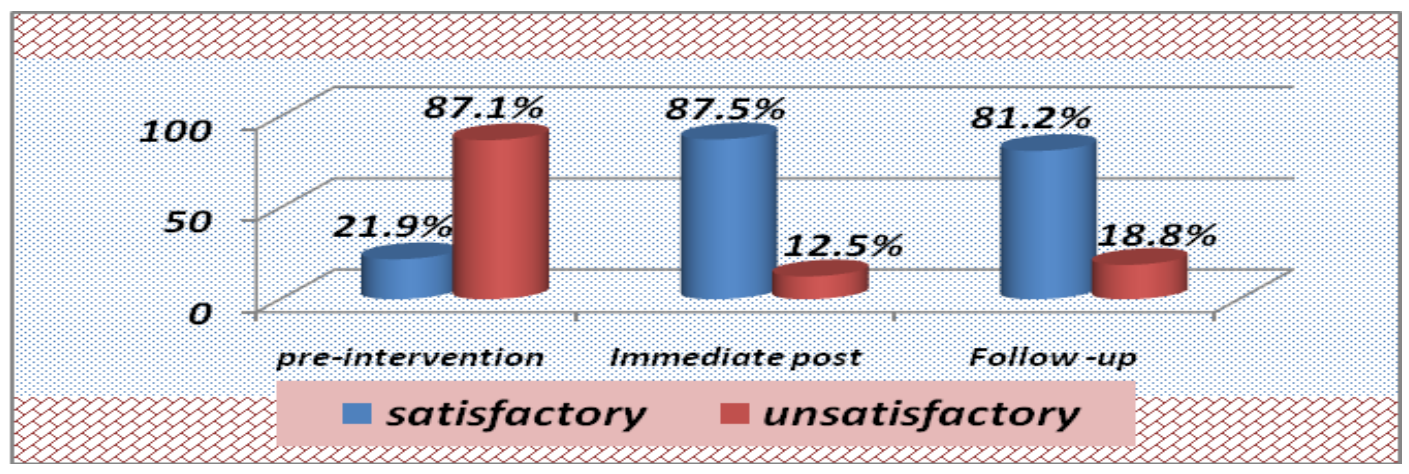

Fig. (2): Percentage distribution of studied nurses' total practice score regarding electrocardiography at different phases of program implementation.

Table (2): Correlation between studied nurses' total knowledge and practice score regarding electrocardiography at different phases of program implementation.

\begin{tabular}{|c|c|c|c|c|c|c|}
\hline \multirow[t]{3}{*}{ Total practice score } & \multicolumn{6}{|c|}{ Total knowledge score } \\
\hline & \multicolumn{2}{|c|}{ Pre-program } & \multicolumn{2}{|c|}{ Immediate post } & \multicolumn{2}{|c|}{ Follow -up } \\
\hline & $\mathbf{r}$ & $\begin{array}{c}\mathbf{P} \\
\text { value }\end{array}$ & $\mathbf{r}$ & $\begin{array}{c}\mathbf{P} \\
\text { value }\end{array}$ & $\mathbf{r}$ & $\begin{array}{c}\mathbf{P} \\
\text { value }\end{array}$ \\
\hline Pre-program & $.543^{* * *}$ & .001 & .170 & .352 & .248 & .171 \\
\hline Immediate post & .171 & .349 & $.851^{* * *}$ & .000 & .081 & .661 \\
\hline Follow -up & .240 & .187 & .348 & .051 & .684 & $.000 * *$ \\
\hline
\end{tabular}

\section{Discussion:}

Firstly, demographic characteristics of the studied nurses:

This study indicated that half of nurses were at the age twenty-five to thirty years old. This might be due to a newly graduate nurses are appointed in the coronary care units. In the same line with Ibrahim et al., (2016), who stated that more than two fifth of studied subjects their age ranged between twenty-five to thirty years old. Disagreed with Malk, et al., (2013)who finding that more than half of nurses were at the age group twenty to twenty-five years old.

As regard of the gender the study revealed that the majority of nurses were females. This might be due to nursing education for males start recently. This result agreed with Ibrahim, et al., (2016) who stated that the majority of them were females.

Related to nurses' educational qualification more than one third of the studied nurses' had technical nursing education, which might explain that they are young and tolerate the nature of the work in CCU. This result agreed with Ali et al., (2012) who stated that most of nurses had technical nursing education. Disagreed with Mahrous et al., (2007) who stated that half of the nurses had bachelor degree.

As regards to marital status, the present study indicated that most of them were married. And according to years of work the 
present study found more than half of the studied nurses' were having from five to ten years of work. This finding agreed with Omran et al., (2010) who stated that majority of the nurses were married with years of experience sex to ten years.

Regarding the nurses' years of experience in CCU half of the studied nurses' were having from one to five years. Supported byAmerican Association of Critical-Care Nurses, (2013) stated that critical care nurses practice in settings where patients require complex assessment, highintensity therapies and interventions, and continuous nursing vigilance. Critical care nurses rely upon a specialized body of knowledge, skills and experience to provide care to patients and families and create environments that are healing, humane and caring.

\section{Secondly: nurses' knowledge regarding electrocardiography.}

The study revealed that the majority of the study nurse had unsatisfactory level of knowledge regarding electrocardiography preprogram implementation this may be due to workload, lack of concentration and insufficient knowledge, overloaded by more duties and having more work hours but there was improved post program implementation where as the majority of nurses had satisfactory level of knowledge regarding ECG. And there was acceptable drop of knowledge regarding ECG at follow up phases where as more than three quarter of them had satisfactory level of knowledge. This might be due to positive impact of an educational program on improving nurses' knowledge regarding electrocardiography.

\section{Thirdly: nurses' practices regarding electrocardiography}

The study revealed that most of the study nurse had unsatisfactory level of practice regarding electrocardiography preprogram implementation this may be due to poor skills and interruptions but there was improved post program implementation whereas most of them had satisfactory level of practice regarding ECG. And there was acceptable drop of practice regarding ECG at follow up phases whereas more than three quarter of them had satisfactory level of practice. This might be reflecting the positive impact of an educational program on improving nurses' practice regarding electrocardiography.

Fourthly: relation between nurses' knowledge and practices regarding electrocardiography to their demographic characteristics:

The current study revealed that were a positive correlation between total nurses' knowledge and practice at pre, post and follow up program implementation. This might due to the training program improved the nurses' knowledge and practice regarding electrocardiography. This result agreed with Hassan and Issa, (2014) who stated that there is a significant relationship and this is a positive side to connect the practical and theoretical.

\section{Conclusion}

Based on the findings of the current study, it can be concluded that majority of the nurses were having an unsatisfactory performance (knowledge and practice) regarding electrocardiography pre the program implementation. Meanwhile, the majority of the studied nurses had got statistically significant improvement in their performance post the program implementation, while this improvement lowered slightly post three months at follow up, which supported the study hypothesis.

\section{Recommendation}

Based on results of the present study the following recommendations can be suggested: 
1. An orientation program should be prepared to help the newly appointment nurses to revise, acquire and develop their knowledge and practice regarding ECG.

2. Continuous in-service training programs about ECG for the purpose of refreshing, updating the nurses knowledge and practice regarding ECG.

3. The importance of establishing booklet guideline for critical care nurses regarding ECG.

4. Regular meetings between nurses and their supervision should be conducted to evaluate and find way for improvement.

5. Further researchers recommended for implementing the educational training program on larger sample selected from different geographical areas of Egypt to raise the efficiency of nurses performance regarding ECG.

\section{References}

Ali, A. S., Mohamed, M. A., Hassan, M. S. and Sobeh, H. S. (2012). Effect of self learning modules on nurses performance regarding electrocardiography. Thesis submitted for partial fulfillment of doctorate degree. Faculty of nursing. Ain Shams university. P.p. 104, $107,108$.

American Association of Critical-Care Nurses. (2013). Available at http://www.aacn.org. Accessed at December 2016.

Basavanthappa, B. (2015). Cardsiovascular Nursing. Medical Surgical Nursing. 3rd ed. Edited by the same authors.Jaypee Brothers Medical Publishers Ltd. India. Pp.,698, 699.

Bucher, L. (2014). Dysrhythmias. Medical Surgical Nursing: Assessment and Management of Clinical Problems. 9th ed. Edited by Lewis, S. L., Dirksen, S .R., Heitkemper, M. M., Bucher, L. and Harding,
M. Mosby, an imprint of Elsevier Inc. Canada. Pp, 799,800.

Clutter, P. (2015). Ventricular Dysrhythmias and Atrioventricular Blocks, EKG Changes other than Myocardial Infarction. EKG for Nursing Demystified. 1st ed. Edited by the same author. McGraw-Hill Education. United States of America. Pp. 240, 286.

Diehl, T.S. (2012). Cardiovascular System. Critical Care Nursing Made Incredibly Easy. 3rd ed. Edited by the same author. Lippincott Williams \&Wilkins.China. P. 270.

Eckman, M. (2013). Electrocardiogram. Lippincott's Nursing Procedures.6th ed. Edited by the same author. Lippincott Williams and Wilkins.China. P. 250.

Fitzpatrick, J. J. (2013). Best Practice Guidelines. Encyclopedia of Nursing Education. 1st ed. Edited by Smith, M. J., Carpenter, R. and Fitzpatrick, J. Springer Publishing Company, LLC. United States of America. P. 37.

Hales, M. (2014). Nursing Care of People with Coronary HEART Disease. Medical-Surgical Nursing Critical Thinking in Client Care. 4th ed. Edited by Lemone, P. , Burke, K., LevettJones, T., Dwyer, T., Moxham, L., Eid-Searl, K., Berry, K., Carville, K., Hales, M., Knox, N., Luxford, Y. and Raymond, D. Pearson Australia Group Pty Ltd.China. PP.1020, 1023.

Hassan, M. F. and Issa, H. S.(2014). Knowledge evaluation theoretical and practical nurses in the electrocardiogram.Journal of international academic research for multidisplinary.2 (6), July.P. 471.

Hinkle, J. L. and Cheever, K. H. (2014).Assessment of Cardiovascular Function. Brunner and Suddarth's Textbook of Medical Surgical Nursing. 12th ed. Edited by the same authors. Wolters Kluwer Health/ Lippincott Williams and Wilkins. China. P. 677.

Ibrahim, R. A., Abd-Allah, K. F., Arafa, O. S. and Mohammed, S. S. (2016). Effect of nursing care standards on nurses performance regarding caring for patients with cardiac 
arrhythmias. Doctoral thesis in medicalsurgical nursing, Faculty of Nursing, Benha University. P. 99.

Ignatavicius, D.D. and Workman, M. L. (2013). Management of Patients with Problems of the Cardiovascular System. Medical- Surgical Nursing Patient Centered Collaborative Care. 7th ed. Edited by the same authors. Saunders, an imprint of Elsevier Inc. United States of America. Pp. 718,731.

Jacob, A., Rekha, R. and Tarachand, J. S. (2015). Advanced Clinical Procedures. Clinical Nursing Procedures: The Art of Nursing Practice. 3rd ed. Edited by the same authors. Jaypee Brothers Medical Publishers. New Delhi. P. 350

Linton, A.D. (2016).Cardiac Disorders. Introduction to Medical Surgical Nursing, 6th ed. Edited by the same autors. Soundaries, an Imprint Elsevier Inc. Canada. Pp. 726,732.

Mahrous, F. M., Abdelaziz, M. M., Attia, M. and Mohammed, E. T. (2007). Effect of Implementing nursing care standards for nurses caring for patients with cardiac arrhythmia, Doctoral thesis in medicalsurgical nursing, Faculty of Nursing, Ain Shams University. P. 94.

Malk R. N., Khalil F. M. Mahammed W.Y. and Taha A.S (2013). Assessment of nurses knowledge and practice in cardiac dysrhythmia among critical ill patients at Benha University Hospital" Master thesis Faculty of Nursing,Benha University. Pp.64.

Marcum, J. (2013). Dysrhythmia Interpretation and Mangement. Introduction to Critical Care Nursing. 6th edition. Edited by Sole, M. L.,
Klein, D. G. and Moseley, M. J. Saunders, an imprint of Elsevier Inc. China. P.94.

Nettina, S. M. (2014).Cardiovascular Function and Therapy. Lippincott Manual of Nursing Practice.10th ed. Edited by the same authors. Wolters Kluwer health \ Lippincott Williams and wilkins. China P. 334.

Omran, E. S., Shoulah, A. S., Mohammed, M. A. and Abdelkader, H. M. (2010). A study of nurses performance management and prevention of complication for patient undergoing cardiac catheterization, thesis submitted for partial fulfillment of the requirements of master degree in nursing science, Faculty of Nursing, Benha University, PP.61,62.

Rahr, R. R and Ayachi, S (2013). Recording an Electrocardiogram. Essential Clinical Procedures. 3rd edition. Edited by Asprey, D.P. and Dehn, R.W. Saunders, an imprint of Elsevier Inc. Philadelphia Pp.86,87.

Tame, S. L. (2013). The effect of continuing professional education on perioperative nurses' relationships with medical staff: Findings from a qualitative study. Journal of Advanced Nursing, 69(4), 817-827.

Williams, L.S. (2015). Nursing Care of Patients with Cardiac Dysrhythmias. Understanding Medical Surgical Nursing. 5th ed. Edited by Williams, L.S. and Hopper, P.D. F.A. Davis Company. Philadelphia. Pp.500,504,511.

Zhu, B., Ding, Y. and Hao, K. (2013).A Novel Automatic Detection System for ECG Arrhythmias Using Maximum Margin Clustering with Immune Evolutionary Algorithm, Computational and Mathematical Methods in $\begin{array}{llll}\text { Medicine } & 9(1) . & \text { P. }\end{array}$ 